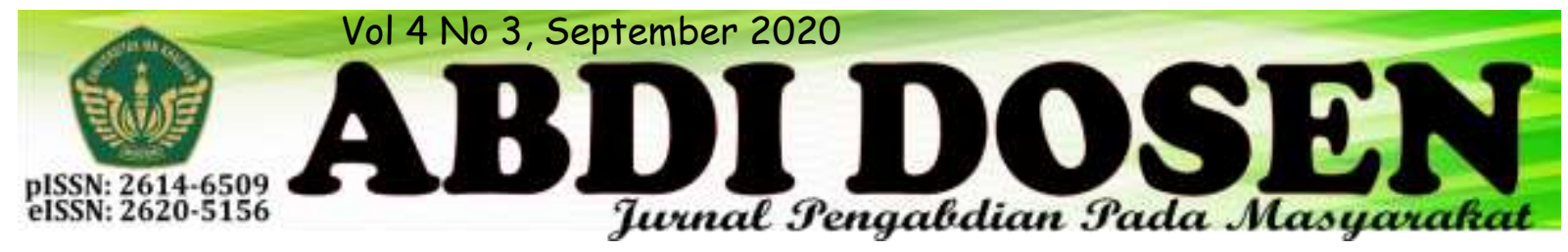

\title{
FAKTOR-FAKTOR YANG BERHUBUNGAN DENGAN TINGKAT PENGETAHUAN REMAJA PUTRI TERHADAP KEBERSIHAN ORGAN GENITAL DI PONDOK PESANTREN DARUSSALAM KABUPATEN BOGOR TAHUN 2018
}

\author{
Fenti Dewi Pertiwi ${ }^{1}$, Merry Maeta Sari $^{2}$, Elyana Sismayanti ${ }^{3}$ \\ fenti.dewi.pertiwi@gmail.com ${ }^{1}$ \\ meta_ssi@yahoo.co.id ${ }^{2}$ \\ elyanasismayan96@gmail.com ${ }^{3}$
}

Konsentrasi Kesehatan Reproduksi dan Kesehatan Ibu Anak (KIA), Program Studi Masyarakat Fakultas Ilmu Kesehatan, Universitas Ibn Khaldun Bogor ${ }^{123}$

\begin{abstract}
Abstrak
Rendahnya pengetahuan remaja tentang kesehatan reproduksi memungkinkan remaja tidak berprilaku higienis dalam menjaga kebersihan organ genital. Tujuan dari penelitian adalah untuk mengetahui faktor-faktor yang berhubungan dengan tingkat pengetahuan remaja putri terhadap kebersihan organ genital di Pondok Pesantren Darussalam Kabupaten Bogor Tahun 2018. Penelitian ini menggunakan desain cross sectional. Sampel dalam penelitian ini 137 responden dengan teknik sampel simple random sampling. Alat yang digunakan dalam penelitian ini adalah kuesioner. Hasil penelitian menunjukkan bahwa ada hubungan antara interaksi teman sebaya ( $\mathrm{p}$-value $=0,030$ ) dengan $\mathrm{OR}=2,356$. Kesimpulan penelitian ini menunjukkan adanya hubungan antara interaksi teman sebaya dengan tingkat pengetahuan remaja putri mengenai kebersihan organ genital. Saran yang dapat diberikan ialah pondok pesantren perlu meningkatkan sistem pembelajaran mengenai kesehatan reproduksi, karena dewasa ini masih banyak remaja putri yang belum mengetahui secara pasti dan menerapkan untuk kebiasaan sehari-harinya.
\end{abstract}

\section{Kata kunci : Organ Genital, Remaja Putri, Pengetahuan}

\section{LATAR BELAKANG}

Menurut Badan Pusat Statistik Provinsi Jawa Barat jumlah penduduk berdasarkan jenis kelamin pada tahun 2016 memiliki kelompok umur (10-14 tahun) dan (15-19 tahun) sebanyak 4,380,522 penduduk laki-laki. Sedangkan kelompok umur (10-14 tahun) dan (15-19 tahun) sebanyak 4,211,955 jumlah penduduk perempuan (BPS Provinsi Jawa Barat, 2016). Kebersihan organ genitalia eksterna adalah menjaga kesehatan vagina dimulai dari memprhatikan kebersihan diri.
Indonesia merupakan daerah yang beriklim tropis, sehingga udara panas dan cenderung lembab sering membuat banyak berkeringat dibagian tubuh yang tertutup dan lipatan-lipatan kulit seperti didaerah alat kelamin. Kondisi ini menyebabkan mikroorganisme jahat terutama jamur mudah berkembang biak, yang akhirnya menimbulkan infeksi (Depkes, 2010). Masalah kesehatan reproduksi di Asia sebanyak $76 \%$ yang mengalami keputihan yang paling sedikit satu kali dalam 
hidupnya. Berdasarkan hasil penelitian menyebutkan bahwa tahun 2010, 52\% wanita di Indonesia mengalami keputihan, kemudian pada tahun 2011, 60\% wanita pernah mengalami keputihan, sedangkan tahun 2012 hampir 70\% wanita di Indonesia pernah mengalami keputihan, dan pada tahun 2013 bulan januari hingga agustus hampir 55\% wanita pernah mengalami keputihan.

Menurut Survey Departemen

Kesehatan Jawa Barat tahun 2011 sekitar 316 orang mengalami infeksi pada genetalia eksternal, dan 592 orang mengalami keputihan pada remaja putri. Rendahnya pengetahuan tentang kesehatan reproduksi akan memungkinkan perempuan tidak berperilaku hygiene pada saat menstruasi yang dapat membahayakan kesehatan reproduksinya sendiri. Menurut data BKKBN (2010) penduduk remaja usia 10-24 tahun sangat beresiko tinggi terhadap kesehatan reproduksi dan pengetahuan remaja mengenai kesehatan reproduksi masih sangat rendah. Survey yang dilakukan Youth Center Pilar PKBI Jawa Tengah (2004), menjelaskan bahwa hanya $19,50 \%$ remaja perempuan yang memiliki pengetahuan yang memadai mengenai fungsi organ reproduksi dan cara merawat organ reproduksi.

Hasil penelitian sebelumnya di Kota dan Kabupaten Bogor pada remaja putri menemukan $57 \%$ dari 81 responden memiliki keluhan keputihan. Hasil penelitian di SLTP Bogor menyatakan bahwa remaja putri yang melakukan perawatan genitalia secara benar pada saat tidak menstruasi sebesar $49,6 \%$ dan sebesar $45,5 \%$ remaja putri yang melakukan perawatan pada saat menstruasi. Hasil ini membuktikan bahwa rendahnya pengetahuan tentang kesehatan reproduksi akan memungkinkan perempuan tidak berperilaku hygiene pada saat menstruasi yang dapat membahayakan kesehatan reproduksinya sendiri (BKKBN, 2011).

Berdasarkan data jumlah proyeksi penduduk Kabupaten Bogor sebanyak 5.459.668 jiwa (BPS Kabupaten Bogor, 2015). Persentase jumlah remaja sebesar $11,03 \%$ terdiri dari laki-laki dan perempuan (SIAK Provinsi Jawa Barat, 2011). Hal ini menjadikan banyaknya penduduk diwilayah kabupaten terutama remaja dengan keadaan yang sangat mudah dan tentu menjadi polemik saat ini sehingga informasi penting pun luput menjadi perhatian. Bidang kesehatan di pesantren belum berfungsi secara maksimal meskipun sudah ada Pos Kesehatan Pesantren, tapi kegiatan promosi dan edukasi kesehatan reproduksi belum berjalan dengan baik. Problem seksualitas dan reproduksi remaja bisa menjadi ancaman serius terhadap potensi pesantren yang didominasi oleh remaja, selain itu adanya keterbatasan sarana prasarana penunjang, dan kurangnya pemahaman menyangkut teknis kerja sama dalam merealisasikan kesehatan reproduksi (Setia, 2013). Salah satu penelitian mengenai kesehatan reproduksi yang telah dilakukan oleh Syukri (2017) di Pondok Pesantren Darussalam Kabupaten Bogor menyatakan bahwa pengetahuan dan perilaku santri mengenai kebersihan diri tergolong buruk, hal ini dikarenakan kurangnya sosialisasi atau promosi kesehatan terlebih mengenai kesehatan reproduksi baik kesehatan reproduksi wanita maupun kesehatan reproduksi lakilaki. Selain itu data yang didapatkan di Kabupaten Bogor remaja putri dengan pengetahuan yang buruk tentang keputihan lebih banyak sebesar $(53,6 \%)$ dalam hal 
tidak mengetahui tentang pencegahan keputihan tersebut.

Berdasarkan studi pendahuluan yang telah dilakukan oleh peneliti di Pondok Pesantren Darussalam Kecamatan Ciomas Kapuaten Bogor pada santriwati mengenai menjaga kebersihan organ genital ditemukan masih banyak yang belum mengerti bagaimana cara membersihkan organ kelamin dengan benar, dan juga masih banyak santriwati yang baru mengetahui tentang organ genitalia bahkan ada beberapa santriwati yang mengalami keputihan berbau tidak sedap, berwarna kekuningan dan terasa gatalselain itu pernah terjadi kasus santriwati mengalami infeksi parah pada alat kelamin dan dilarikan ke pelayanan kesehatan.Hal ini dikarenakan masih belum adanya infromasi yang memadai tentang pentingnya menjaga kebersihan organ genital pada wanita. Adapun tujuan penelitian ini adalah untuk mengetahui

\section{METODE}

Desain penelitian ini menggunakan Cross Sectional dengan menggunakan pendekatan kuantitatif, penelitian crosssectional penelitian untuk mempelajari dinamika korelasi antara faktor-faktor dengan efek, dengan cara pendekatan, observasi atau pengumpulan data sekaligus pada suatu saat (point time approach) (Notoadmodjo, 2010). Penelitian ini untuk melihat faktor-faktor yang berhubungan dengan Tingkat Pengetahuan Remaja Putri mengenai Kebersihan Organ Genital di Pondok Pesantren Darussalam Kabupaten Bogor Tahun 2018, dengan pengumpulan data yang dilakukan dalam waktu yang bersamaan antara variabel dependen dan variabel independen. Populasi dalam penelitian ini adalah remaja putri dengan populasi 202 responden. Sampel yang telah diketahuinya hubungan sumber informasi dengan tingkat pengetahuan, diketahuinya hubungan interaksi teman sebaya dengan tingkat pengetahuan, dan diketahuinya hubungan dukungan guru dengan tingkat pengetahuan terhadap kebersihan organ genital.

Ruang lingkup penelitian ini untuk mengetahui faktor-faktor apakah yang berhubungan dengan tingkat pengetahuan remaja putri terhadap kebersihan organ genital di Pondok Pesantren Darussalam. Penelitian ini merupakan jenis penelitian deskriptif yang bersifat kuantitatif. Populasi dalam penelitian ini adalah remaja putri sebanyak 50 responden dengan teknik simple random sampling di Pondok Pesantren Darussalam Kabupaten Bogor. Data primer dikumpulkan dengan membagikan kuesioner. Penelitian ini dilakukan pada bulan Juli-Agustus di Pondok Pesantren Darussalam Kabupaten Bogor Tahun 2018.

digunakan berjumlah 137 responden. Penelitian ini terdapat tiga variabel yaitu variabel independen mencakup faktor sumber informasi, faktor interaksi teman sebaya, dan faktor dukungan guru sedangkan variabel dependen berupa tingka pengetahuan mengenai kebersihan organ genital pada remaja putri.

Teknik pengumpulan data dengan menggunakan kuesioner dengan jumlah 40 pertanyaan. Adapun analisis data dalam penelitian ini menggunakan analisis data univariat meliputi tingkat pengetahuan, sumber informasi, interaksi teman sebaya dan dukungan guru. Dan analisis bivariat penelitian ini untuk melihat hubungan antara variabel dependen yaitu tingkat pengetahuan dengan variabel independen yaitu hubungan sumber informasi terhadap 
kebersihan organ genital, hubungan interaksi teman sebaya terhadap kebersihan organ genital dan hubungan dukungan guru terhadap kebersihan organ genital. Untuk membuktikan adanya hubungan antara dua variabel tersebut digunakan uji Chi-Square.

\section{HASIL}

\section{1) Hubungan antara Interaksi Teman Sebaya dengan Tingkat Pengetahuan mengenai Kebersihan Organ Genital}

Hasil penelitian menunjukan, terdapat 90 responden memiliki interaksi teman sebaya dimana 59 responden $(65,5 \%)$ dengan tingkat pengetahuan baik dan 31 responden $(34,4 \%)$ memiliki interaksi tetapi dengan tingkat pengetahuan kurang. Serta 47 responden tidak memiliki interaksi teman sebaya terhadap tingkat pengetahuan mengenai kebersihan organ genital dimana 26 responden $(55,3 \%)$ dengan tingkat pengetahuan kurang mengenai kebersihan organ genital dan 21 responden $(44,7 \%)$ memiliki tingkat pengetahuan baik mengenai kebersihan organ genital. Seperti pada tabel 3.1 berikut ini

Tabel 3.1 Distribusi Interaksi Teman Sebaya dengan Tingkat Pengetahuan Remaja Putritenang Kebersihan Organ Genital di Pondok Pesantren Darussalam Kabupaten Bogor Tahun 2018

\begin{tabular}{|c|c|c|c|c|c|c|c|c|}
\hline \multirow{3}{*}{$\begin{array}{c}\text { Interaksi Teman } \\
\text { Sebaya }\end{array}$} & \multicolumn{4}{|c|}{ Tingkat Pengetahuan Remaja Putri } & \multirow{2}{*}{\multicolumn{2}{|c|}{ Total }} & \multirow{3}{*}{$\begin{array}{c}\text { OR } \\
(95 \% \mathrm{CI})\end{array}$} & \multirow{3}{*}{ p-value } \\
\hline & \multicolumn{2}{|c|}{ Pengetahuan Baik } & \multicolumn{2}{|c|}{ Pengetahuan Kurang } & & & & \\
\hline & $\mathrm{N}$ & $\%$ & $\mathrm{~N}$ & $\%$ & $\mathrm{n}$ & $\%$ & & \\
\hline Ada Interaksi & 59 & 65,5 & 31 & 34,4 & 90 & 100 & 2,356 & \\
\hline Tidak ada Interaksi & 21 & 44,7 & 26 & 55,3 & 47 & 100 & $(1,146-$ & 0,030 \\
\hline Jumlah & 80 & 58,4 & 57 & 41,6 & 137 & 100 & $4,845)$ & \\
\hline
\end{tabular}

Dari hasil uji statistik diperoleh nilai $\mathrm{p}$-value $=0,030$. Oleh karena nilai $\mathrm{p}<\alpha$ $(0,05)$, maka dapat disimpulkan bahwa terdapat hubungan yang bermakna antara interaksi teman sebaya dengan tingkat pengetahuan mengenai kebersihan organ genital. Serta dari uji statistik juga di dapat nilai OR sebesar 2,35 kali artinya responden yang tidak memiliki interaksi

\section{PEMBAHASAN}

\section{1) Hubungan Sumber Informasi dengan Tingkat Pengetahuan mengenai Kebersihan Organ Genital}

Hasil penelitian ini menunjukan tidak ada hubungan yang bermakna antara sumber informasi dengan tingkat pengetahuan mengenai kebersihan organ teman sebaya terhadap tingkat pengetahuan mengenai kebersihan organ genital berpeluang 2,35 kali lebih besar untuk menjaga kebersihan organ genital dibanding dengan responden yang memiliki interaksi teman sebaya terhadap tingkat pengetahuan mengenai kebersihan organ genital.

genital dan ditemukan data bahwa responden yang tidak terpapar terhadap tingkat pengetahuan mengenai kebersihan organ genital berpeluang 0,76 kali lebih besar untuk tidak menjaga kebersihan organ genital dibanding dengan responden yang terpapar terhadap tingkat pengetahuan mengenai kebersihan organ 
genital. Hal ini sesuai dengan penelitian yang dilakukan oleh: Indriani (2012) mengenai Hubungan Akses Media Massa dengan Pengetahuan Kesehatan Reproduksi pada Remaja. Teori yang dikemukakan oleh Grapindo (1998) Sumber adalah dasar yang digunakan dalam penyampaian pesan-pesan, yang digunakan dalam rangka memperkuat pesan itu sendiri.Sumber dapat berupa orang, lembaga, buku dan sejenisnya. Selain itu pengertian informasi adalah keterangan, pemberitahuan, atau berita. Informasi juga sifatnya menambah pengetahuan atau wawasan. Jadi sumber informasi mengenai kebersihan organ genital di Pondok Pesantren sudah tergolong baik dalam hal mendapatkan infromasi, akan tetapi hal ini menjadikan santriwati mendapatkan infromasi tidak secara keseluruhan dikarenakan tidak diperbolehkannya membawa peralatan elektronik, jika pun diperbolehkan dalam keadaan terdesak.

\section{2) Hubungan Interaksi Teman Sebaya dengan Tingkat Pengetahuan mengenai Kebersihan Organ Genital}

Hasil penelitian menunjukkan adanya hubungan yang bermakna antara interaksi teman sebaya dengan tingkat pengetahuan remaja putri mengenai kebersihan organ genital. Hal ini sesuai dengan penelitian yang dilakukan oleh Lestari (2014) mengenai "Hubungan Pengetahuan Menstruasi dan Komunikasi Teman Sebaya dengan Personal Hygiene" menunjukan bahwa pengetahuan hygiene sangat penting dalam meningkatkan derajat kesehatan reproduksi wanita, oleh karenanya diperlukan informasi melalui komunikasi teman sebaya. Menurut teori Umairoh (2013) menyatakan bahwa remaja putri (santriwati) merasa nyaman membicarakan mengenai personal hygiene (kebersihan organ genital) dengan orang yang sebaya dengan dirinya, dengan pengetahuan yang menurut mereka sama atau sederajat, sehingga remaja putri lebih banyak mengeksplorasi pertanyaan dan mendiskusikan hal tersebut dengan nyaman tanpa ada rasa malu. Kelompok teman sebaya memberikan dukungan yang kuat pada remaja, dengan demikian kelompok teman sebaya memiliki pengaruh yang kuat pada evaluasi diri dan perilaku remaja.

\section{3) Hubungan Dukungan Guru dengan Tingkat Pengetahuan mengenai Kebersihan Organ Genital}

Hasil penelitian menunjukan tidak ada hubungan yang bermakna antara dukungan guru dengan tingkat pengetahuan mengenai kebersihan organ genital. Hal ini sesuai dengan penelitian yang dilakukan oleh: (1) Prapto (2008) mengenai Faktor - Faktor yang Berpengaruh terhadap Praktek Kesehatan Reproduksi Remaja; (2) Solehati dkk. (2017) yang menyatakan bahwa tidak ada dukungan guru yang bermakna dengan perilaku perawatan diri saat menstruasi pada remaja putri. Dengan demikian hasil yang telah dilakukan peneliti dengan hasil yang dilakukan oleh orang lainadanya kesesuaian, bahwa tidak ada hubungan antara dukungan guru terhadap kebersihan organ genital.

Di Pondok Pesantren Darussalam Bogor sendiri, ustadzah atau ustadz masih menganggap partisipasi ustadzah atau guru belum atau tidak penting dalam memberikan infromasi seputar kesehatan reproduksi karena merupakan suatu hal yang sangat tabu dan pandangan yang cenderung menyerahkan kebersihan organ genital khususnya dalam hal praktek tergantung remaja putri itu sendiri. 
Sehingga ustadzah atau guru tidak mau ikut campur dalam hal praktek dan tidak pernah memberikan informasi tentang kesehatan reproduksi secara mendalam,

\section{KESIMPULAN}

Berdasarkan hasil penelitian yang telah dilakukan di Pondok Pesantren Darussalam Kabupaten Bogor tahun 2018 dapat disimpulkan bahwa: (1) tidak terdapat hubungan yang bermakna antara sumber informasi dengan tingkat pengetahuan mengenai kebersihan organ genital pada remaja putri; (2) terdapat hubungan antara interaksi teman sebaya dengan tingkat pengetahuan mengenai kebersihan organ genital pada remaja, dan; (3) tidak terdapat hubungan yang

\section{DAFTAR PUSTAKA}

Amalia R, Allaily. (2016). Gambaran Tingkat Pengetahuan Remaja Tentang Kebersihan Organ Genetalia Eksterna.Skripsi.Jakarta : Universitas Islam Negeri Syarif Hidayatullah.

Deissy, Marcelien Nanlessy et al. (2013).

Hubungan antara Pengetahuan dan Perilaku Remaja Puteri dalam Menjaga Kebersihan Alat Genital dengan Kejadian Keputihan Di SMA NEGERI 2 PINELENG. Ejournal Keperawatan (e-Kp). Volume 1. Nomor 1, 2-4.

Dinas Kesehatan Provinsi Jawa Barat. (2016). Profil Kesehatan. Bandung : Dinkes Jabar

Donggori, I Ratna. (2012). Skripsi. Hubungan Akses Media Massa dengan Pengetahuan Kesehatan akan tetapi jika sudah terjadi kasus langsung segera di rujuk, hal ini sesuai dengan hasil wawancara yang dilakukan pada para ustadzah atau guru.

bermakna antara dukungan guru dengan tingkat pengetahuan mengenai kebersihan organ genital pada remaja putri.

Saran ditujukan kepada Pondok Pesantren agar meningkatkan informasi dan materi dalam pengajaran mengenai kesehatan reproduksi pada remaja terutama. Serta kepada Pelayanan Kesehatan agar senantiasa melakukan penyuluhan ke Pesantren tentang pentingnya menjaga kesehatan reproduksi.

Reproduksi pada Remaja. Jurnal Media Medika Muda. Universitas Diponegoro.

Firdaus, M Aziz. (2012). Metodologi Penelitian. Tangerang Selatan: Jelajah Nusa

Hastono, Sutanto Priyo. (2016). Analisis Data pada Bidang Kesehatan. Jakarta: PT Raja Grafindo Persada

Kurniawan, P Tri. (2008). Tesis. Faktor Faktor yang Berpengaruh terhadap Praktek Kesehatan Reproduksi Remaja. Semarang: Universitas Diponegoro.

Maidartati, Sri hayati et al. (2016). Hubungan Pengetahuan dengan Perilaku Vulva Hygiene pada saat Menstruasi Remaja Putri. Jurnal 
Ilmu Keperawatan. Volume

Nomor , 2-4

Muna, Khoirul. (2016). Skripsi. Pengaruh Interkasi Teman Sebaya Terhadap Perilaku Penggunaan Internet pada Siswa Kelas XI SMK N 2 Yogyakarta. Yogyakarta: Universitas Negeri Yogyakarta.

Nazira \& Devy. (2015). Pengaruh Personal Reference, Thought and Feeling terhadap Kesehatan Reproduksi Santri Putri. Jurnal Promkes. Volume 3 Nomor 2, hal 1

Nissa Queen, Rahayuningsih, dan Hasan. (2015). Kesehatan Reproduksi Remaja Putri di Pondok Pesantren Sidoarjo Jawa Timur. MKB. Volume 47 Nomor 2, hal 1

Notoatmodjo, Soekidjo. (2010). Metodologi Penelitian Kesehatan. Jakarta: PT Rineka Cipta.

Nurlita, Widya. (2014). Skripsi. Gambaran Tingkat Pengetahuan dan Perilaku Menjaga Kebersihan Organ Genitalia Eksterna pada Siswi MI Pembangunan. Jakarta: Universitas Negeri Syarif Hidayatullah.

Pertiwi, D. F., \& Hariansyah, Muhammad Prasetya, P. E. (2019). Faktor Risiko Stunting Pada Balita Dikelurahan Mulyaharja Tahun 2019. PROMOTOR Jurnal Mahasiswa Kesehatan Masyarakat, 2(5).
Poltekkes Depkes Jakarta I. (2010). Kesehatan Remaja : Problem dan Solusinya. Jakarta: Salemba Medika.

Pranata, Setia et al. (2013). Pesantren dan Upaya Pendidikan Kesehatan Reproduksi Remaja (Pesantren and Adolescent Reproductive Health Education Effort). Buletin Penelitian Sistem Kesehatan. Volume 16 Nomor 3.

Ristiana, Nurul. (2016). Skripsi. FaktorFaktor yang Berhubungan dengan Praktik Personal Hygiene Organ Genitalia Eksterna pada Santriwati di Pondok Pesantren Al-Uswah. Semarang: Universitas Negeri Semarang.

Sandriana, IndraFajarwatilbnu et al. (2014). Perilaku Personal Hygiene Genitalia Santriawati di PondokPesantrenUmmulMukminin. Makassar: Sulawesi Selatan.

Sidik, A Tiara. (2015). Hubungan Media Informasi dengan Tingkat Pengetahuan Kesehatan Reproduksi pada Santri. Jurnal Kesehatan Masyarakat. Volume 3 Nomor 3, 2-6

Tetti, Solehati et al. (2017). Hubunngan Sumber Informasi dan Usia Remaja Puteri dengan Perilaku Perawatan disaat Menstruasi. Jurnal Keperawatan. Volume 5 Nomor 2, 24. 